(c)

\title{
RETÓRICA ESCÉNICA Y TÉCNICA ACTORAL. PARADIGMA DE LA CONSTRUCCIÓN DE EMPATÍA EN LA INTERFAZ ESCENA/ESPECTADORES
}

\author{
SCENIC RHETORIC AND ACTING TECHNIQUE. PARADIGM OF \\ EMPATHY BUILDING IN THE SCENE/SPECTATOR RELATIONSHIP
}

\author{
Aldo Rubén Pricco \\ Universidad Nacional de Rosario \\ (aldopricco@gmail.com)
}

https://orcid.org/0000-0002-2589-4755

\begin{abstract}
(C)
DOI: https://doi.org/10.32621/acotaciones.2020.44.04 ISSN 2444-3948

Resumen: En los fenómenos teatrales la construcción de creencia estética y empatía en los espectadores resulta constitutiva. La teatrología indagó esta problemática y ha sido, desde la retórica clásica, una preocupación técnica relevante vinculada con la captura perceptual, la seducción y el impacto afectivo de los discursos escénicos. Ante la preeminencia en Argentina de estudios basados en perspectivas semióticas, en este artículo se formulan, desde un punto de vista del rol de investigador-artista, las vinculaciones entre retórica y teatro en cuanto a los procedimientos de configuración de verosimilitud que permiten conformar un paradigma de la relación escena/espectadores pertinente para la interpelación de los objetos de estudio actuación teatral y puesta en escena.
\end{abstract}

Palabras Clave: teatralidad; retórica; verosimilitud; empatía; seducción escénica. 
Abstract: In theatrical performances, the building of aesthetic belief and empathy on spectators is a whole. This matter has been looked into by theatrology and it has been, since classical rhetoric, a relevant technical preoccupation linked to perceptual capture, spectator seduction and affective impact of scenic discourse. In this article, given the preeminence in Argentina of studies based on semiotic perspectives, from the point of view of the researcher-artist role, links between rhetoric and theatre are formulated concerning the procedures of verisimilitude configuration that form a scene/spectator relationship paradigm, pertinent to the theatrical acting and staging question.

Key Words: theatricality; rhetoric; verisimilitude; empathy; scenic seduction.

Sumario: 1. Introducción. 2. Perspectiva retórica y el diseño de la verosimilitud: efecto de organicidad y adhesión empática en la tradición retórica. 4. Efecto de «verdad» $\mathrm{y}$ «creencia» espectatorial: admirabilidad y «demora». 5. Contagio cenestésico y empatía. 6. Conclusiones. 7. Obras citadas. 8. Notas.

Copyright: (C) 2020. Este es un artículo abierto distribuido bajo los términos de una licencia de uso y distribución Creative Commons 4.0 Internacional (CC BY 4.0)

Aldo Rubén Pricco Doctor en Humanidades y Artes y Posdoctorado en Teatro por la Universidad Nacional de Rosario, Argentina (UNR). Actor, director, docente e investigador teatral. Profesor en Letras. Director del Centro de Investigaciones Teatrales (FHyA, UNR). Catedrático de «Introducción a la tradición técnica escénica de Occidente», «Retórica escénica» $y$ «Metodología de la investigación escénica», Licenciatura Artes Escénicas/UNR. Director del «Teatro de la Universidad», Elenco Oficial de Teatro/UNR. Ha dictado seminarios y publicado trabajos de su especialidad en universidades de Alemania, Argentina Brasil, Colombia, España y Portugal. Autor de Sostener la inquietud. Teoría y práctica de la actuación teatral según una retórica escénica (Biblos, 2015). 


\section{INTRODUCCIÓN}

Tanto en la retórica como en las artes escénicas el propósito de influir afectivamente sobre otros (incluida la producción del pathos en términos aristotélicos) habilita la construcción de programas de control discursivo en el que los diagnósticos sobre la recepción inherente a un arte convivial como el teatro devienen imprescindibles. Cuáles son los presupuestos para la supervivencia de la atención y mantenimiento de la condición espectatorial configuran reflexiones ineludibles para pensar, por ejemplo, una retórica de lo dramático o, más precisamente, de la escena, es decir, un conjunto de procedimientos vinculados con la apelación a configuraciones discursivas tanto verbales como somáticas y procedimientos escénicos montados sobre la búsqueda de efectos perlocutivos de seducción ajena en el marco de convenios lúdicos. En ese encuadre, los contratos de visión de una cultura (y las rupturas que luego se institucionalizan), por un lado, y las leyes y principios de afectación de los sentidos desde la actividad escénica, por el otro, resultan instrumentos de peso para indagar no solo acerca de la «máquina retórica», sino también respecto de las construcciones de la categoría «espectador» y las relaciones fundantes de la copresencia de todo espectáculo:

Por ende, abordamos parcialmente aquí el objeto de estudio de la mutualidad entre agentes escénicos y auditorio a partir del estado de cosas en algunas especulaciones filológicas y teatrológicas y la adecuación al hic et nunc que todo discurso está obligado a llevar a cabo dentro de una perspectiva retórica propia de una especie —el teatro- signada por la copresencia en el acto de enunciación escénica.

La hipótesis central de nuestro trabajo (asistida por la tradición técnica retórico-actoral y por la propia praxis) formula que, en la medida en que no se adviertan divorcios psicofísicos —obviamente controlados y no sujetos a patologías-, la actuación teatral resultará verosímil (en términos de credibilidad estética y no de naturalidad o analogía con la cotidianeidad) y estará, por ende, en condiciones de provocar la empatía necesaria para una copresencia sostenida. 
Resulta necesario plantear cuál es nuestra perspectiva «retórica». Una definición operativa de retórica podría resumirse como el conjunto de estrategias discursivas tendientes a modificar voluntad y creencia en los receptores. Aunque generalmente se enfatiza el género judicial de la retórica clásica, ello no impide que haya una constante en la relación retórica que Aristóteles percibió claramente y que la cultura romana desarrolló hacia un incipiente pragmatismo lingüístico sobre el que se asienta definitivamente la retórica latina: es, precisamente, la relación entre los sujetos, lo que supone un locutor y un interlocutor (o un auditorio). Se encontrará más tarde esta relación bajo diferentes formas. Una de ellas la constituye la relación entre agentes escénicos de un espectáculo y los eventuales espectadores. En esa circunstancia no habrá demostración sino fascinación; no existirá persuasión en el sentido de una convicción que conduzca al hacer sino a la experiencia estética de la ficción convenida por un claro contrato. Se trata de conmocionar mediante la fictio durante el tiempo pactado del crédito estético hacia el artefacto denominado representación teatral, performance, en síntesis, actio, acción.

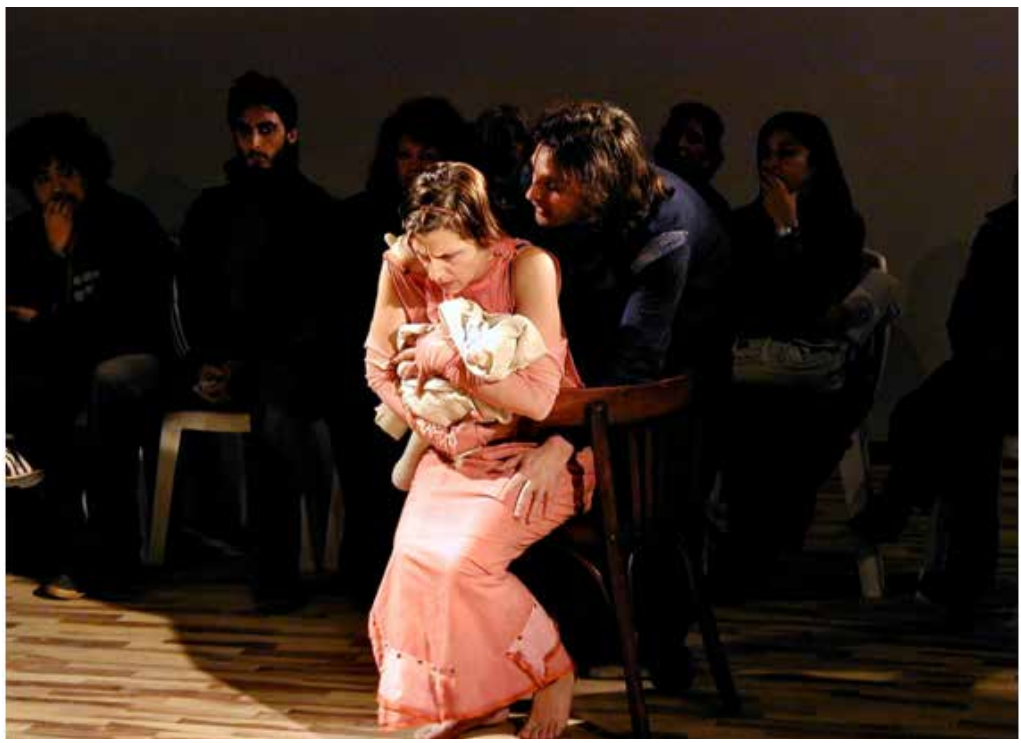

Andrómaca (Silvia Ferrari) y Talthibios (Ulises Moset) en Troyanas. Versión mixta de Eurípides / Séneca. Puesta y dirección de Aldo Pricco (2006-2007). Teatro de la

Universidad UNR. Fotografía de Lucas Pricco. 
Con cierto itinerario común, gran parte de las investigaciones semióticas del teatro del siglo XX se han cimentado desde los marcos teóricos de la lingüística, la narratología, y la teoría literaria, lo que configura un hecho que ha aportado puntos de vista diversos para tratar de abarcar el fenómeno. El marco de la teatrología, entendido como el estudio de la práctica teatral como totalidad y autonomía, es decir, dramaturgia, puesta en escena, representación, recepción y circulación, supera la parcialización y/o el apartamiento de disciplinas diversas como la semiótica, sociología, antropología, historiografía teatrales, y se ha proyectado desde el siglo XX hacia una visión epistemológica de acuerdo con que el hecho teatral comporta un proceso global y unitario. A la vez, esta macrovisión integradora de varias fases disciplinares, incluye itinerarios metodológicos diferentes que, sin embargo, han pivoteado en torno del privilegio de la cuestión de la construcción del sentido. Frente a este estado de cosas, una perspectiva "pragmática»" ${ }^{1}$ es decir, de búsqueda de efectos del discurso escénico sobre la recepción, emerge con fuerza al contrastar la teoría teatral de las últimas tres décadas con las especulaciones de la retórica grecolatina.

Al respecto, llama la atención el conjunto de similitudes entre los praecepta retóricos y los intentos de una regulación del arte teatral, sobre todo en lo atinente a los criterios del uso del cuerpo en el espacio y el tiempo de la escena. Estas coordenadas, legitimadas por la presencia de los espectadores, obligan a los actores a seguir una serie de protocolos predeterminados que, de acuerdo con la tradición (Vicentini, 2012), garantizarían la eficacia del acto teatral.

Lo que une las prácticas retórica y teatral es el delgado corredor de la verosimilitud. Si bien ambas se realizan en el ámbito de la performance, una la disimula - la retórica - y otra la expone —el teatro-. En la cultura occidental, desde el mundo grecolatino en adelante, la convención, el hábito y la tradición concuerdan en que la representación de un texto dramático es una performance (Schechner, 2000). Los patrones repetitivos constituyen, por ende, una performance y se ajustan a los esquemas organizativos, tanto de la máquina retórica como de una dramaturgia, de una teoría de la puesta en escena, en general, y de la actuación, en particular (Pricco, 2015).

Un modo «pragmático» de comprender el fenómeno escénico es vincularlo con lo indispensable de la influencia sobre otro (el destinatario, el espectador, el oyente). Mientras que la performance retórica influye, o 
trata de influir, escudándose en una «inocencia» de manipulación que oculta su estrategia, la performance teatral propiamente dicha denuncia su índole repetitiva y ficcional, aunque tanto una como otra requieran de un mismo efecto de «espontaneidad» para ser creídas.

$\mathrm{Al}$ respecto, una frecuente preocupación desde la Antigüedad en este terreno consiste en el logro de una sensación de correspondencia entre la expresión de una idea y/o sentimiento y el estado mental o emocional del ejecutante, acompañada de la empatía (Sofía, 2015) a modo de un sentimiento común de acercamiento o rechazo emocional capaz de incidir en el destinatario. Como si no alcanzara con la imitación plena -que luego Denis Diderot plantearía como problema en la Paradoja acerca del comediante- ya desde el Ion de Platón circula la concepción de un matrimonio entre el universo de la vivencia y el de la expresión actoral y una necesidad de provocar estados anímicos particulares en los oyentesvidentes a partir de la verosimilitud (es decir desde una coherencia). Así aparece esta demanda en Horacio, Ars poética, 102-103, en la que se aconseja (en un formato de índole didáctica y técnica) al actor: «Si querés que llore, tenés que sufrir vos en primer lugar: solo después tus infortunios me van a lastimar». ${ }^{2}$

Evidentemente, este clásico pasaje horaciano sigue el canónico ensamble entre caracteres, pasiones y comportamiento. Sin que esta prescripción sea homologada totalmente al entusiasmós al que hace referencia Platón en Ion - esa ejecución de la inspiración divina que ejecutan actores y rapsodas y el consecuente contagio empático y/o cenestésico一, es posible visualizar la misma noción de «emoción en el actor» como indispensable para la del espectador. ${ }^{3}$

3. EFECTO DE ORGANICIDAD Y ADHESIÓN EMPÁtica EN LA TRADICIÓN RETÓRICA

Cabe consignar que partiendo de la concepción de la existencia de un lenguaje «natural» y de otro «artificial», la Retórica de la Antigüedad (Aristóteles, Cicerón, Quintiliano) distinguió dos dimensiones. Una, vinculada con el «uso corriente» del discurso, y otra, relacionada con el trabajo artístico, es decir, técnico. Si la primera supone una «transparencia» —que no es tal—, la segunda opera en una opacidad construida 
por la intervención metódica sobre el discurso (tanto verbal como corporal), lo que originaría un «desvío» del uso pretendidamente «neutro». ${ }^{4}$

Sabemos que esas disquisiciones aristotélicas intentaron dar cuenta de un fenómeno mucho más amplio, consistente en la intencionalidad manifiesta de un hablante no ya de comunicar una idea, informar o expresar un sentimiento sino de influir emocionalmente sobre su interlocutor, para lo que se relevan de la empiria - los contrapuntos de argumentos, los enfrentamientos judiciales, etc. - los mecanismos de elección y combinación de la lengua y el cuerpo capaces de atrapar al receptor y afectar no solo su forma de pensar sino también -y sobre todo- sus emociones y su voluntad. Es entonces cuando emerge la figura del «desvío», del corrimiento de las funciones habituales (semánticas) del lenguaje en general hacia empleos manipuladores, para lo que resulta necesario disponer de dispositivos y sistemas técnicamente organizados para tal fin.

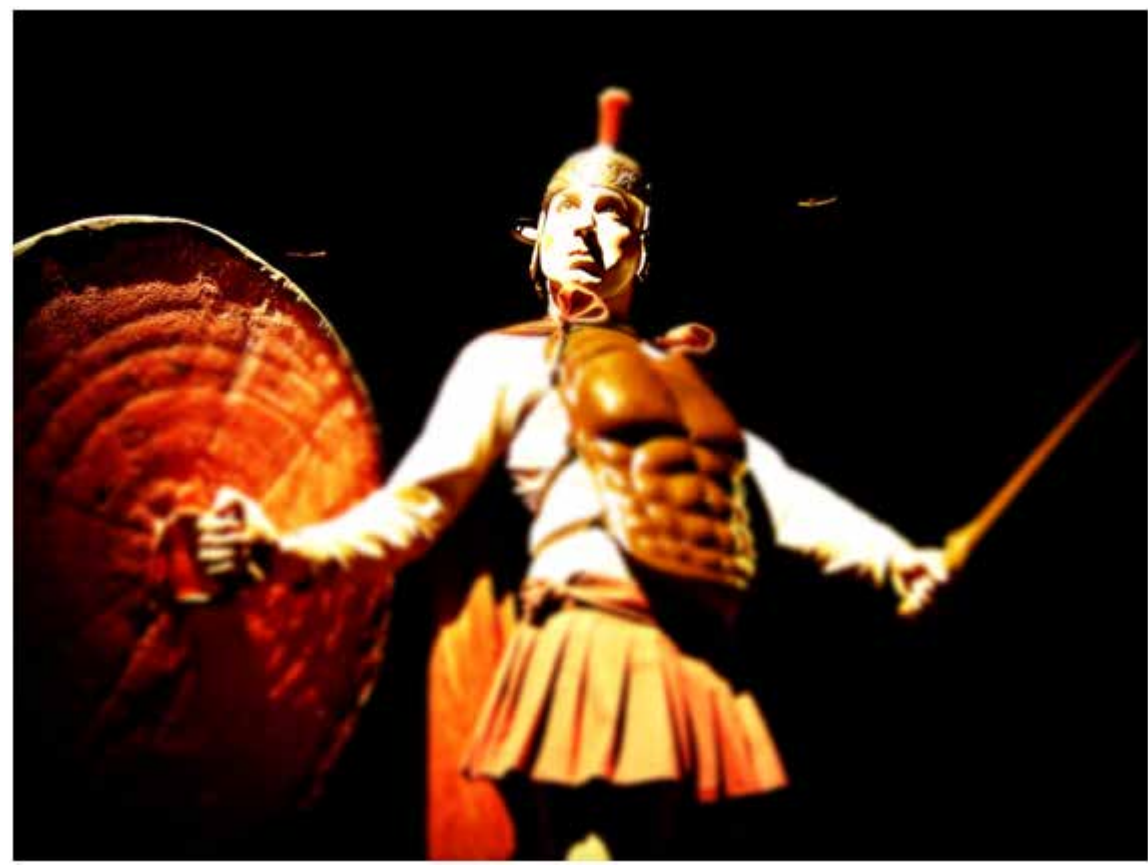

J. P. Yévoli en El soldado fanfarrón de Plauto. Traducción, puesta en escena y dirección de Aldo Pricco (2006-2013). Teatro de la Universidad (UNR). Fotografía de Lucas Pricco 
En ese sentido, tanto Cicerón como Quintiliano, cuyos tratados circularon durante siglos en Europa como manuales de técnica interpretativa, prescriben modalidades del uso del cuerpo ostentado e insisten acerca de la necesidad de construir el efecto de correspondencia entre el sentimiento de la entidad escénica y su manifestación somática.

Quintiliano trata ampliamente el tema de la actio (homologamos «acción» a acción teatral). El libro XI de su Institutio Oratoria configura un completo recorrido expositivo, reflexivo y didáctico que recoge la tradición sobre las reglas y consejos técnicos para la creación y exposición de discursos. ${ }^{5}$ Se observa en el rhetor del siglo I d.C. una preocupación por dotar al cuerpo escénico - técnica mediante- de un efecto de reciprocidad entre el estado de ánimo actoral y el de los espectadores. Ya en el siglo I d.C. Quintiliano, atento a seguir la concepción ciceroniana, se hace cargo de la postura en el libro VI de Inst., 2, XXVI:

El principal precepto para mover los afectos — según me parece- es que en primer lugar estemos movidos nosotros. Porque, por cierto, sería una ridiculez el aparentar llanto, ira e indignación en el semblante si esto no pasara en nuestro interior. ¿Qué otro motivo hay para que uno que padece una calamidad que le acaba de suceder prorrumpa en exclamaciones expresivas, y para que otro, aunque sea un hombre iletrado, hable con elocuencia cuando está enojado, sino el que en tales ocasiones habla la fuerza del alma y los afectos verdaderos? ${ }^{6}$

El rhetor de Calahorra va, incluso, más allá al postular una lógica de la afectación del receptor durante la performance mediante la construcción del efecto de vivencia del pathos. Así, en el mismo libro, capítulo 2, parágrafos del XXVII al XVIII, se observa claramente la lógica de la fusión de los sujetos enunciadores real y retórico o escénico:

Por lo cual, si queremos hablar con verosimilitud, hemos de parecernos en los afectos a los que sienten de verdad, y hablar con aquella viveza de sentimientos de la que queremos se revista el juez. ¿Cómo va a sentir dolor éste si ve que yo no lo siento? ¿Cómo se va a irritar si no se irrita el orador que pretende excitar en aquél esta pasión? O ¿cómo va a llorar si ve al orador muy sereno? No puede ser, porque ninguno se abrasa sino con el fuego, ni se ablanda sino con las lágrimas, ni alguno puede dar el 
color que no tiene. Primeramente, pues, nos debemos mover nosotros y sentir compasión si queremos que se mueva el juez. ${ }^{7}$

Como puede apreciarse, es toda una instrucción técnica teatral sobre la composición de las pasiones de tal modo que estas impacten y afecten emocionalmente al destinatario. Los preceptos retóricos se funden aquí con los utilizados y transmitidos por ciertos paradigmas de la tradición del arte del actor en occidente. Esta concordancia resulta esperable dada la franja de interacción que comparten el agente retórico y el escénico: la constitución de alteridad y su mantenimiento a través de la constitución de empatía.

Algo similar ocurre con la Rhetorica à Herennium, atribuida a Cicerón. Resulta claro que este tratado pivotea sobre la dificultad de establecer protocolos de performance pero ello no es un obstáculo para un intento de fijar el efímero próximo:

No ignoro el enorme trabajo que me he impuesto al intentar expresar los movimientos del cuerpo con palabras y reproducir con la escritura las entonaciones de las voces. Realmente no creí que se pudiera tratar por escrito de estas cosas con éxito. Pero aunque eso fuera imposible, no pensaba que lo que hacía iba a ser inútil, pues quise apuntar aquí lo indispensable, el resto lo dejamos para la ejercitación. Sin embargo, conviene saber lo siguiente: una buena pronunciación consigue que el asunto parezca surgir del ánimo. ${ }^{8}$

Esta última afirmación corrobora la preocupación por el logro sin fisuras de un engaño, un simulacro, una ficción que no debe denunciar su condición puesto que lo importante es que el «asunto parezca surgir del ánimo», es decir, de la espontaneidad y «verdad» y no de un guión o partitura verbal, gestual, proxémica y quinésica que el orador (el actor) ha preparado minuciosamente. He aquí, en la disciplina retórica, una evidente interpretación teatral en la que el componente destinatario ignora que participa de una convención y percibe y entiende el discurso, por consiguiente, como parte del universo de lo real, como continuidad de su cotidiano, como verosímil. Se trata de la creación de un estado anímico particular en el destinatario y, de allí, la necesidad imperiosa de conmover y deleitar, acciones que, como componentes básicos del montaje 
de una actuación, devienen rasgos comunes entre la técnica actoral y la tradición retórica.

En estas situaciones de conformación de la rutina de la presencia ante los receptores - una interfaz-, el principio técnico resulta la propia creencia del orador en las situaciones y vicisitudes de su relato o interpretación, de modo tal que solo la simultaneidad de estados emocionales, en el marco de una asociación lúdica, habilitaría la performance para ser creída y, por ende, afectar al destinatario. Es esa la manera de entender el artilugio de la ars que se argumenta en Quint., 2. XXXIV y XXV:

Cuando sea preciso mover la compasión, persuadámonos de que pasa por nosotros la desgracia de la que nos lamentamos poniéndonos en el mismo trance. En una palabra, pongámonos en lugar de aquellos a quienes les ha sucedido la calamidad de que nos quejamos, no tratando la cosa como si pasase por otro, sino revistiéndonos por un instante de aquel dolor. De este modo vamos a hablar como si tuviéramos el sufrimiento de alguna calamidad. Yo mismo he visto actores y cómicos que después de algún paso tierno, quitada la máscara, salían llorando. Y si sola la pronunciación de lo que otro escribió puede tanto para los afectos, ¿qué vamos a hacer nosotros, que debemos imaginarnos la misma cosa, para que parezca que nos encontramos movilizados por la misma calamidad del que se ve en peligro? ${ }^{9}$

Como cita de auctoritás y experiencia, la práctica forense del rhetor de Calahorra, cierra el capítulo 2, para otorgar valor probado a sus dichos prescriptivos:

¿Cómo nos vamos a revestir de estas personas si nos olvidamos de sus pasiones? No debía omitir estas reflexiones, las que, cualquiera que sea o haya sido mi habilidad pues creo que no me han tenido por poco listo, me sirvieron tanto para moverme a mí mismo, que no solo me sacaron lágrimas de los ojos sino que me hicieron aparecer en el rostro la palidez y sentimiento con una gran verosimilitud. ${ }^{10}$

La fusión de lo predeterminado y la actuación propiamente dicha genera, así, la captatio benevolentiae para la constitución de alteridad expectante y su mantenimiento. En ese sentido, se advierte, asimismo, en De oratore ciceroniano una atención sobre la índole psicofísica de la atrac- 
ción que conviene ejercer sobre la audiencia-videncia, ya que una y otra vez se vuelve sobre la preeminencia, como en el teatro, de lo afectivo-estético por sobre lo puramente intelectivo. Ahora, el logro de la configuración de esa empatía requiere de una utilización del cuerpo del orador (podríamos homologarlo al actor) con ajuste a ciertas pautas técnicas. Así se dispone en Cic. De orat., III, LIX, 220-221, acerca de la performan$c e$, en especial, el protocolo de los gestos y de la labor de los ojos:

Es propia del ánimo, en efecto, toda la acción, y la imagen del ánimo es el rostro, sus delatores los ojos; y esta es la única parte del cuerpo que puede lograr tantas significaciones [y mutaciones] cuantos movimientos de ánimo hay.[...] Los ojos están, en verdad, para que, ya con su enojo, ya con su sosiego, ya con su fijación, ya con su hilaridad, signifiquemos los movimientos de los ánimos de manera adecuada al género mismo del discurso: la acción es, en efecto, como un lenguaje del cuerpo, y por ello debe ser más concorde con la mente [...] la acción, que exhibe el movimiento del ánimo, mueve a todos: por los mismos sentimientos, en efecto, son sacudidos los ánimos de todos los hombres, y mediante las mismas señales los reconocen estos en los otros, y en sí mismos los indican. ${ }^{11}$

Nótese la síntesis de los consejos en cuanto a la importancia del manejo voluntario y preciso del gesto y de la mirada a fin de alcanzar la adhesión emocional, la acción como vehículo para esa afectación y la simultaneidad entre la referencia pasional de la expresión y esta. Nos enfrentamos al valor de menti congruens ciceroniano, una categoría integrante de la verosimilitud por la cual resulta creído aquello que no expone separadas las instancias de sus componentes. Las pautas técnicas de esta organicidad ${ }^{12}$ se apoyan en un efecto de espontaneidad producto de la repetición, ensayo y precisión de una rutina. Son, justamente, las performances teatrales, en el sentido que Schechner (2000) les otorga, las que operan en la realidad como una ceremonia pautada pero, a la vez, integrante de una «naturalidad» convencional que las vuelve creíbles por la coherencia de su sistema interno. Esta coherencia se establece a partir de ciertos preliminares de credibilidad asentados en la moderación y el decorum propio de las nociones de «gestus, non bic verba exprimens scaenicus, sed universam rem et sententiam non Jemonstratione, sed significatione Jeclaran»»: un gesto que no interprete «escénicamente» lo dicho sino que 
solo lo signifique, es decir, que no sea dominado el corporis motus por el exceso, la ampulosidad y una redundancia expresiva. ${ }^{13}$ Es clara la intención de borrar el artificio de modo tal que la performance no sea percibida como tal sino como única y primera en su desarrollo. Una pretensión que forma parte de un gran sector de la tradición teatral independientemente del estilo de la puesta en escena. Queremos decir que no se trata de la morfología de un naturalismo decimonónico de la gestualidad y de la acción sino de una ligazón entre la forma final de la actuación, su motivo aparente y su impulso. ${ }^{14}$

\section{EFECTO DE «VERDAD» Y «CREENCIA» ESPECTATORIAL: ADMIRABILIDAD Y «DEMORA»}

Como se ve, subyace la hipótesis de que la técnica puede suplir la «verdad», o su efecto, mediante el artilugio de la fusión entre el sujeto real y el representado. Se trata de asumir los mismos objetivos a través de una mimetización que derivaría de un compromiso entre los protocolos del agente retórico y/o escénico mediados por la lógica del «como si» que, en la búsqueda de una matriz de verosimilitud, sistematizará unos cuantos siglos más tarde Stanislavski. ${ }^{15}$

De una u otra forma, pareciera que la conjetura de construcción de creencia en el espectador resulta una constante diacrónica de diversas culturas teatrales. Para el logro de esa creencia Salabert (1995) formula consideraciones acerca de la pasión, la razón y la creencia:

Lo razonable que hay en la razón ya ha dimitido en provecho de otra cosa o se ha dejado invadir por otra facultad, la «creencia». Si la razón es un instrumento de la inteligencia con el que esta, siempre insegura, se expande y diversifica, la creencia es una deriva en la que el raciocinio es seducido por dos flancos a la vez: la imaginación por un lado y la afectividad por el otro. Diferente al saber, en el creer la inteligencia no ha desaparecido; solo ha puesto su razón a descansar. [...] Por eso en el fondo toda creencia es un saber confiado que no encuentra necesidad alguna de contrastarse con la experiencia real. (Salabert, 1995: págs.14-15)

Para conseguir ese «saber confiado», la escena dispone de dispositivos que, adecuándose a cada estilo teatral, atraviesan (y sustentan) 
la praxis al modo de estrategias de composición (visual y auditiva) y captación y mantenimiento de la atención espectatorial: un conjunto de procedimientos que alteran la pasividad del público por medio de la concreción de estímulos que «extrañan» la conducta de las entidades teatrales. La acción propiamente dicha de los cuerpos actorales y el modo de dar a ver configuran la base de las tácticas para construir una pulsión, una necesidad de consumo perceptivo y emocional que debe ser elaborada con la técnica.

Justamente, la creación del núcleo de esa necesidad reside en lo atractivo de alguna forma de «belleza», entendida como una cualidad de fascinación que los individuos devenidos espectadores experimentan frente a cuerpos escénicos, es decir, puestos en foco, ostensibles. Preferimos nombrar así el entramado de variables que provocan placer estético: belleza. Ahora bien, esta palabra tan funcional para discursos plenos de subjetividad, bien puede entenderse como una noción superadora de la dispersión. Es, en realidad, una condición de admirabilidad la que establece la pulsión de ver, de percibir en general. El aparato perceptual humano debe ser convocado por la necesidad de activarse y sustentarse. Sin embargo, pareciera que las opciones por las cuales la escena y su vida crean y absorben el interés estuviesen diseminadas por una explosión de subjetividades sujetas a diversas variables. ¿Podrá pensarse —al menos como hipótesis - una cierta unidad de lo admirable?

Aunque Giordano Bruno haya dicho que no existe nada que sea absolutamente bello sino solo para alguien (Tartarkjewicz, 1976, pág. 243) y por más que para algunos «lo bello» ya no es una noción actual y solo cabe postularla por detrás de otros valores como lo nuevo, lo interesante, lo expresivo, lo novedoso, lo espectacular o lo sublime, es viable pensar esa categoría de atracción más allá de especulaciones en las que se la vinculaba con aspiraciones ideales de verdad, de bondad, de armonía o equilibrio.

Se puede decir que las intenciones de reducir la belleza a un concepto capaz de cubrir todas sus alternativas han sido numerosas en la cultura occidental y los puntos de vista han sido tan diferentes como las disciplinas que abarcó. Las denominaciones, sus criterios, las áreas del arte involucradas en el afán nomenclador de esa noción esquiva se han fundamentado conforme a las configuraciones históricas, sociales, económicas y culturales. Esto implica que las diversas constelaciones e intereses respecto de una restricción del concepto de belleza dependen 
en gran medida de las variables materiales, semánticas y estéticas por las cuales esa belleza «se da a ver»y «se enuncia». Evidentemente existe entre lo dado a ver y los discursos sobre ese fenómeno cierta complejidad no exenta de problematizaciones.

Sin embargo, más allá de la evolución de la noción desde la antigüedad clásica, en la que se la asoció moralmente con «lo bueno» y lo trascendente, y las posteriores disquisiciones en las que predominaron los parámetros del orden, la perfección y la proporción para arribar luego del Renacimiento a aquello que puede transmitir sensaciones, nuestro propósito es asignar al concepto su estrecha vinculación con el goce estético. Esta sensación parece relacionada con la satisfacción que experimenta un receptor ante el evento artístico, en nuestro caso, teatral. La provocación de sentimientos más que de ideas reside en la base de «lo bello». El proceso de mudanza que la acepción ha tenido en occidente parece no abandonar el proceso de inducción de un placer que en distintas épocas ha sido construido y experimentado por estímulos diversos (como en el caso de las vanguardias europeas de principios del siglo XX). No se trata solo de un significado sino de una experiencia de confrontación de la que surge un goce que en primera instancia es sensorial. En ese sentido, lo feo, lo horroroso, lo inquietante y la crueldad revisten condiciones de incentivos de placer y el deleite puede emerger justamente de lo horroroso, o frente a la experiencia de lo negativo, de lo confuso, de lo siniestro, de lo arbitrario, de lo caótico. No habría, entonces, una dispersión total de acuerdo con las subjetividades sino una elemental base de estímulo que causa en quienes miran y escuchan un cierto deleite independiente de la reflexión sobre el mismo. Por lo expuesto, no hacemos referencia a los cánones respecto de la belleza sino a la persistencia de un tipo de relación entre el artefacto teatral y su audiencia-videncia: como sea, un goce desinteresado es experimentado por el espectador desde el sustento de sus sentidos y no bajo el presupuesto de sus opiniones.

Por ello, dado el acto consciente del público de "ponerse a mirar», el discurso escénico deberá construir una «belleza», la urgencia de ser visto. Por ende, los cuerpos actorales y su entorno están obligados a provocar en los receptores una considerable cuota de caída de reflexividad, a absorber las distancias e inducir a un «vivir la escena» al mismo tiempo que la actuación y su espacio dejen percibir también que se trata de una ficción: «un ver-viviendo al tiempo que un ver-mirando es lo 
que la representación escénica exige del espectador para alcanzar toda su efectividad» (Salabert, 1990, pág. 86). Esta dualidad de estado en el espectador puede instaurarse mediante un hacer escénico que ofrezca «confusiones» y promesas de esclarecimiento:

La aparente condición de perdido (o confuso) por parte del actor, y su tardanza en recuperar un equilibrio que el espectador considera necesario, conduce a este mismo espectador a experimentar una sensación de extrañeza o de terror. Dicha sensación solo puede resolverse, de modo provisional, en la justeza o el equilibrio. Y se resolverá provisionalmente, porque de manera casi inmediata irá a caer de nuevo en su contrario: en un nuevo desequilibrio. [...] El personaje teatral...y su lucha interna ha de conducir por simpatía a una ruptura en la continuidad del pensamiento lógico del espectador. La discordia entre el personaje y su presencia (o la persona física que es el actor y el personaje) ha de tener la fuerza de una promesa. Pero una promesa cuyo cumplimiento, al ser siempre insatisfactorio o provisional, producirá un efecto seguro: mantener la atención, hacer que sigamos mirando. Y seguir mirando ¿no supone ya una espera? Es la espera de algún sentido que habrá de constituir la finalidad de lo que vemos como un conglomerado de signos. Desajuste, pues. Y, por ahí, discontinuidad, intermitencia. Intermitencia en la lógica de la percepción o en la del pensamiento es lo mismo, puesto que la lógica de la percepción nunca prescinde largo tiempo del pensar que se adelanta, le toma la delantera y dice qué hay que percibir...pensable. Por ello, y de modo general, todo lo que existe y constituye el objeto simple y superficial de la experiencia para la lógica del pensar podría ser visto en algún momento como una reducción estética de la realidad a un estado virtual de energía en estado puro. Es la caída del pensar en la percepción simple. Solo que esta reducción pasa entonces por la desaparición momentánea, breve - es el momento estético de ruptura-, de las correspondencias pensables entre las cosas. (Salabert, 1990, págs. 96-97)

Este efecto de desacople provoca una sensación de falla en el conjunto razonable de las cosas, un desajuste por el que se filtra el interés perceptual, una desviación, una grieta en el tejido liso de la percepción cotidiana (Salabert, 1990, pág. 98). En esas condiciones, el uso del cuerpo del actor en el espacio y el tiempo y sus relaciones provocan un 
espacio vacío de la recepción, un punto ciego en el que el sujeto espectador proyectará un llenado posible. En eso consiste la admirabilidad, en singularizar algo que está ausente y por ende, impulsa la reposición en el receptor. Así, en un juego antagónico, una parte se muestra y otra se oculta al modo del erotismo visual (y auditivo) al mostrar algo que se oculta ofreciéndose: «enseñar escondiendo está en la base de la espectacularidad» (Salabert, 1990, pág. 103). Un cuerpo se propone, llama la atención, sin embargo, lo visible es otra cosa que tal vez no está presente, que se mantiene escondida o al margen, demorada en su aparición inminente. Estamos haciendo referencia a un principio básico de la presencia escénica: conservar una parcela de secreto en la conducta ficcional a fin de eludir constantemente ese ajuste quizá lógico entre lo real y lo imaginario a lo que propende el espectador.

Para aquel ajuste surge una dicotomía funcional en la Antropología Teatral: ${ }^{16}$ a la concepción del quehacer «cotidiano» se contrapone la del «extracotidiano» (Barba, 2010), producto del trabajo (en términos de acumulación de energía extra), del «cultivo» y de toda una operatoria que corre de «su lugar» el discurso para «llevarlo a otro sitio». El hecho de reconducir, de desviar de su curso «natural» el uso del discurso, se convierte en un seducere, un apartamiento buscado por el agente discursivo, lindante con las necesidades de Jelectare (deleitar) y commovere (conmover afectivamente) indispensables para «montar» la atracción del espectador de la que Eisenstein y Meyerhold (De Marinis, 2005) dieron cuenta y que se vinculan con la «admirabilidad».

En esa dirección, la hipótesis que Eisenstein desarrolla de manera paralela al «montaje de atracciones» es la del movimiento expresivo de los agentes escénicos, capaz de «irradiar», en tanto sujetos de aquella manipulación de la atención, un contagio psicofísico en los destinatarios (Eisenstein, 1986). Habría allí un vínculo con las relaciones retórica/ teatro (Cicerón, De oratore, II, XLV, 187-188; 190-191 y Quintiliano, Inst., II 2, XXVI, XXVII al XXX, XXIV y XXXV).

Para Eisenstein resultan «expresivas», o sea, «orgánicas»y, por ende, eficaces, las acciones que el actor ejecuta con todo su cuerpo, incluyendo en ello gestos, utilización de la voz, etc., y que involucran la totalidad del organismo en tanto poseen su origen en el centro de gravedad y no revisten un carácter superficial o periférico. Estas acciones expresivas/ orgánicas cumplirían una doble característica: a) suscitar en quien las cumple un cierto estado de ánimo emotivo elemental (el presupuesto 
ciceroniano de De oratore, II, XLV, 190-191) y b) provocar en el espectador una determinada respuesta, crear una emoción. La respuesta buscada consistirá en un estado de ánimo análogo al del actor -la pretendida interpretación que se hizo de la actuación stanislavskiana (Eines, 2011) -y que, hipotéticamente, pasará al espectador por una «contagiosidad mímica», un conjunto de efectos y reacciones de la sensación y percepción del movimiento que desembocan en la cenestesia (Barba, 2010). Se trataría de una presuposición de transferencia hacia el público.

Por ello, Aristóteles planteaba lo xené, lo extraño o no habitual, como modo de convocar la atención espectatorial al definir la lexis retórica (elocutio, la elección de figuras de pensamiento y de lenguaje luego codificadas) como «extraña» (xéne), «extranjera», distinta de la oikeia, la «familiar», es decir, aquella forma del lenguaje cuyo sentido se capta sin reflexión, «se entiende por sí sola» y provoca o bien ninguna, o bien muy pocas asociaciones de significado. La lexis retorizada provoca un extrañamiento porque produce una convergencia deliberadamente buscada entre un significado literal y otro asociado a él que se impone por sugestión (Aristóteles, Retórica, III, 2, 5). Aquella obviedad del interés por lo nuevo, ajeno, discontinuo, extraordinario o anómalo como motor de la captación ajena implica una continuidad de las tendencias perceptivas que forman parte del ideario de cualquier performer.

Una noción como la de «organicidad»-perezhivanie- (Stanislavski, 1979; Serrano, 2014), esa correspondencia entre emoción y gestus, objeto de estudio de las especulaciones sobre la técnica actoral (Savarese, 2015), tal vez no resida tanto en la experiencia emotiva del actor sino en su simulacro y/o efecto: una vez más los modos de vinculación entre scaena y cavea resultan factores de la constitución de creencia (Peirce, 1988). La permanencia e irresolución de los procedimientos más eficaces para el logro de esa «sensación de vida» u «organicidad» configuran un problema particular diseminado en épocas y culturas diferentes que, mediante una perspectiva comparatística, habilita poner en contacto preceptivas antiguas y algunas hipótesis que las neurociencias aplicadas al fenómeno teatral (Falletti, 2010; Sofia, 2015) han aportado en los últimos veinte años. Mucho antes de los años 90, en los que los estudios sobre neuronas-espejo alcanzaran su cruce con el teatro, Eisenstein formulaba la manipulación sensorial del montaje de las atracciones (De Marinis, 2005), un criterio desarrollado también en la concepción de «acción» de Selden (1972). 


\section{Contagio cenestésico y empatía}

En los numerosos tratados del siglo XVIII (Vicentini, 2012) y hasta la Antropología teatral de fines del XX (Barba y Savarese, 1990) las polémicas entre las posturas «emocionalistas» $\mathrm{y}$ las «imitativas» respecto de la pasión ficcional en la técnica dialogan en los umbrales de la paradoja de Diderot (2006). En efecto, para este y para Antoine-François Riccoboni (1971) - a diferencia de lo sostenido por su padre, Luigi (1979) - la participación emocional interior del actor era insuficiente (Riccoboni, 1971, pág. 51). De uno u otro modo y más allá de la fusión o no fusión de los estados afectivos de actor y personaje, lo pertinente parece resultar la lúdica adhesión al artificio que no exhibe su factura, es decir, que el espectador no note - o no le importe- el andamiaje técnico que sostiene la actio (Pricco, 2015).

La cualidad de atracción del movimiento expresivo (es decir, el efecto psicológico y psicofísico que tiene sobre el público, calculado con anticipación) se garantiza, en primer lugar, porque cada momento de enfrentamiento dialéctico entre sujetos escénicos o de trabajo real y finalizado atrae hacia sí la atención misma del espectador; en segundo lugar, porque el movimiento expresivo asegura que las emociones previstas afloren en el público. Es, precisamente, el movimiento expresivo, construido sobre una base orgánica adecuada, el único capaz de suscitar esta emoción en el espectador (Aumont, 1992), quien, de forma refleja y atenuada, repite todo el sistema de movimiento del actor: como resultado de los movimientos realizados, «las tensiones musculares embrionarias del espectador se descargan en la expresión deseada». (Eisenstein 1981, págs. 63-70).

De este modo, se advierte una búsqueda de lo que las neurociencias aplicadas al teatro hipotetizan sobre el denominado «espacio de acción compartido»(Sofía, 2015: 94-109): una empatía, una co-constitución del espacio y de las sensaciones homologable a la cenestesia a la que se refiere Barba (2010; 2017), una condición de «espectatoriedad»subsumida por la seducción escénica (scaena) y el impacto en la corporeidad del espectador (cavea). Así, el sistema de neuronas-espejo regula -a nivel pre-reflexivo, pre-cultural- las relaciones interpersonales a través de un proceso de simulación que genera no solo en quien actúa, sino también en quien observa un espacio de acción compartido, un mismo estado de modificaciones motoras, corpóreas y emotivas: 
El arte del actor, por lo tanto, reside en el activar intenciones y en modificar el arco de desarrollo previsto por el proceso sensorial-motor, al inhibirlo - dado que la acción es, precisamente, potencial- o transformarlo mediante la duda o la inquietud, desencabalgamientos o desorientaciones. Se trata de hacer una apuesta sobre el sentido, explotando la previsibilidad para producir la apertura a lo imprevisto y, con ello, a una nueva visión. (Mariti, 2010, pág. 139).

De acuerdo con Trancón (2006), en la experiencia del espectador la clasificación entre cognición y emoción es más analítica que real, habida cuenta del hecho de que no existe pensamiento sin emoción, ni emoción sin pensamiento. Sin embargo, hay teatralidades en las que predomina la operación cognitiva o racional ${ }^{17} \mathrm{y}$ otras en las que se destaca el preeminencia emotiva o afectiva. La noción de predominio sirve para no provocar discrepancias artificiales entre fenómenos concurrentes y complementarios durante el espectáculo, por más que sean, a la vez, opuestos (Trancón, 2006, pág. 336). En ese sentido, una plataforma de operaciones escénicas tendientes a la adhesión afectiva de los espectadores, es decir, de su constante convocatoria emocional e intelectiva, podrá tener en cuenta una serie de «placeres»-el Jelectare y, por ende, el commovere retóricos - a provocar a través del uso del tiempo, el espacio, las corporalidades, las acciones, los gestos, las proxemias y el tipo de vínculo físico-espacial entre entidades escénicas y espectadores.

Al respecto, Salabert (1990) plantea que el «incumplimiento informativo» (Pericot, 1987) de la escena no debería causar pensamiento pleno en el espectador o alejamiento del suceso de ficción. El vacío, ese hiato, hueco o entidad inacabada, debe estar «lleno» y no constituir un vacío «vacío». Pura promesa, productor de espera (sats en la denominación de Barba, 2010), el «agujero» escénico debe salir a impedir que el público formalice «puentes» con su actividad racional al no soportar horror vacui- lo incompleto (Gombrich, 1999; Arnheim, 2001; Del Estal, 2010). Actuar teatralmente constituye, por ende, «un estímulo constante de esperanzas de futuro acontecer» en los receptores. Por ese motivo no conforma un «en sí» sino un «entre»-una interfaz-, que basa su eventual eficacia - sostener la inquietud e interés del espectador- en el conocimiento y cumplimiento de leyes y tendencias perceptivas, tanto culturales como biológicas, inscriptas en una retórica escénica: se trata de los comportamientos somáticos en el «aquí y ahora» capaces de pro- 
vocar en otros interés y empatía: estados que resultan la razón de ser de los encuentros conviviales.

Por ello resulta pertinente el tránsito por especulaciones que comprenden la Fenomenología de la percepción (Merleau-Ponty, 1994; 1977), la Psicología de la percepción (Ehrenzweig, 1976) y la teoría de la Gestalt (Arnheim, 2001; 1985; Gombrich, 1999; 1987; Kanizsa, 1998), la retórica escénica (Salabert, 1990; Pricco, 2015), la filosofía del teatro (Dubatti, 2014), la antropología teatral (Barba, 2017; 2010; 1992), y las neurociencias aplicadas al teatro (Falletti, 2010; Mariti, 2010; Sofía, 2015).

\section{Conclusiones}

Es en el marco de las consideraciones que anteceden donde se configuraría un trabajo que permitiera entretejer una teoría de lo teatral capaz de correrse de la preeminencia de puntos de vista semánticos y semiológicos y se atendiera, por consiguiente, el fenómeno de la «relación teatral», ${ }^{18}$ esa interfaz fundante de todo evento teatral: el intento y propuesta de describir un paradigma de criterios y estrategias posibles pertenecientes al arte de la manipulación perceptiva y emocional, esa maniobra que fundamenta la máquina de seducción permanente devenida escena, cuerpos actorales, luz, escenografía, espacio y tiempo capaces de construir y mantener la presencia expectante del público.

No resulta arriesgado postular que la construcción y el abordaje del objeto de estudio y las conclusiones provisorias habrán de suponer un enfoque y unos resultados no habituales en las especulaciones sobre el fenómeno teatral, dado que resulta general explorar la dinámica de la escena desde presupuestos semióticos, historiográficos, sociales, etc., sin delimitar el estatuto propio de un arte convivial. Una investigación, de cuyo núcleo resulta este trabajo, problematiza e indaga - y espera obtener resultados verosímiles sujetos a falibilidad - una dimensión de la praxis teatral, lindante con la retórica, y no pensada como una condición de expectación dada de antemano y, por ende, no sujeta a revisión. La revisión que proponemos, entonces, es vincular constantemente la praxis escénica con la operatoria de captatio benevolentiae, de provocación de empatía. ${ }^{19}$ 
La construcción de credibilidad estética y de empatía -y la recurrencia de sus perspectivas y procedimientos - se fundamenta en la mutualidad ontológica entre escena y público, la que provee de hipótesis divergentes tanto para estudios posteriores como para criterios de práctica artística y académica. En ese sentido, se estaría en condiciones de problematizar teorías y prácticas teatrales en la formación específica, no solo en el ámbito artístico sino también en el académico, lo que impactaría en los modos de interpelación de los objetos de estudio de la actuación teatral, de la puesta en escena y de los análisis de bibliografía tradicional a la luz de la necesidad de seducción constante de los artefactos y agentes escénicos para el logro de atracción placentera y empatía.

En definitiva, el efecto de vitalidad por la fusión de lo predeterminado por la técnica y el momento -aquí y ahora - de la acción escénica, el cumplimiento de tendencias y leyes de la percepción humana, la atención a cada estado de cultura y sus verosímiles, la búsqueda de experiencia estética en la que no esté ausente el goce, la edición (montaje) de las partes por encima de cada unidad, la reserva o incumplimiento de lo dado a ver y escuchar configuran módulos ineludibles de un paradigma de la construcción de la empatía indispensable de todo fenómeno teatral más allá de poéticas específicas.

\section{Obras citadas}

Aristóteles (1971). Retórica. Madrid: Instituto de Estudios Políticos. Arnheim, Rudolf (1985). El pensamiento visual. Buenos Aires: Eudeba. Arnheim, Rudolf (2001). Arte y Percepción visual. Madrid: Alianza. Aumont, Jacques (1992). La imagen. Barcelona: Paidós.

Aumont, Jacques (1998). La estética hoy. Madrid: Cátedra Austin, John Langshaw (1962). How to do Thingd with Words. Oxford: Clarendon Press.

Barba, Eugenio (2010). Quemar la casa. Orígenes de un director. Buenos Aires: Catálogos

Barba, Eugenio (2017). La luna surge del Ganges. Mi viaje a través de las técnicas de actuación asiáticas. Buenos Aires: Ediciones del Camino. Barba, Eugenio y Savarese, Nicola (1990). El arte secreto del actor. México: Escenología-UNAM.

[Cicerón, M. T.] (1991). Rhetorica ad Herennium. Barcelona: Bosch. 
Cicerón, M. T. (1995). De Oratore. México: UNAM.

Del Estal, Eduardo (2010). Historia de la Mirada. Buenos Aires: Atuel.

De Marinis, Marco (2005). En busca del actor y del espectador. Comprender el teatro II. Buenos Aires: Galerna.

Diderot, Denis (2006). Paradoja del comediante. Buenos Aires: Losada.

Dubatti, Jorge (2014). Filosofía del Teatro III. El teatro de los muertos. Buenos Aires: Atuel.

Ehrenzweig, Anton (1976). Psicoanálisis de la percepción artística. Barcelona: G. Gili.

Eines, Jorge (2011). Repetir para no repetir. El actor y la técnica. Barcelona: Gedisa

Eisenstein, Sergei (1981). Movimenti espressivi come tecnica per il «Teatro delle Attrazioni» (Solivetti, Carla ed.). Stilb, num. 2, 31-33.

Eisenstein, Sergei (1986). Il montaggio delle attrazioni, en Montani, Pietro, Il montaggio (pp. 219-225). Venezia: Marsilio.

Eisenstein, Sergei (2001). Hacia una teoría del montaje. Vol. 1. Edición a cargo de Michael Glenny y Richard Taylor. Barcelona: Paidós.

Falletti, Celia (et al.) (2010). Diálogos entre Teatro y Neurociencias. Bilbao: Artezblai.

Gombrich, Ernst (1999). El sentido del orden. Madrid: Debate.

Horacio (2012). Arte poética. Introducción, traducción, notas y comentario de Juan Antonio González Iglesias. Madrid: Cátedra.

Kanizsa, Gaetano (1998). Gramática de la visión. Barcelona: Paidós.

Lipps, Theodor (1924). Aesthetik, [1903-1906]. Los Fundamentos de la estética. T. I y II. Trad. esp. de Ovejero Maury. Madrid: Daniel Jorro

Magarshack, David (2007). Prólogo, en Stanislavski, Constantin, El arte escénico (pp. 9-97). México: Siglo XXI.

Mariti, Luciano (2010). Más allá del dogma de la inmaculada percepción. En Falletti, Clelia (et. al.), Diálogos entre teatro y neurociencias (pp.131-155). Bilbao: Artezblai.

Merleau-Ponty, Maurice (1977). Sentido y Sinsentido. Barcelona: Península.

Merleau-Ponty, Maurice (1994). La fenomenología de la percepción. Barcelona: Planeta Agostini.

Peirce, Charles (1988). La fijación de las creencias, en Peirce, Charles, El Hombre, un signo (pp. 175-223). Barcelona: Editorial Crítica.

Pericot, Jordi (1987). Servirse de la imagen. Barcelona: Ariel. 
Platón. (2010). Ion. Buenos Aires: Eudeba

Pricco, Aldo Rubén (2015). Sostener la inquietud. Teoría y práctica de la actuación teatral según una retórica escénica. Buenos Aires: Coedición Biblos/UNR Editora.

Quintiliano. M. F. (1942). Instituciones Oratorias. Madrid: Hernando. Riccoboni, Antoine François (1971). L' art ju théâtre. Geneve: Slatkine Reprints.

Riccoboni, Louis (1979). Dell'arte rappresentativa (rist. anast. 1728). Bologna: Forni.

Salabert, Pere (1990). La mirada en el vacío. Ensayos de estética y semiótica. Poetica et Analytica no 9. Aarhus Universitet: Almen Semiotik, 85-106.

Salabert, Pere (1995). El amor pasional. Una intención y veinte razones, en Area, Lelia.; Ortiz, Graciela (comp.), Pasiones en el siglo XX (pp. 11-51). Rosario: Homo Sapiens.

Savarese, Nicola (2015). Teatri romani: Gli spettacoli nell'antica Roma. Bologna: Cue Press

Schechner, R. (2000). Performance. Teoría y prácticas interculturales. Buenos Aires: Libros del Rojas-UBA.

Selden, Samuel (1972). La escena en acción. Buenos Aires: Eudeba.

Serrano, Raúl (2004). Nuevas tesis sobre Stanislavski. Fundamentos para una teoría pedagógica. Buenos Aires: Atuel.

Serrano, Raúl (2014). Lo que no se dice. Una teoría de la actuación. Buenos Aires: Atuel.

Sofía, Gabriele (2015). Las acrobacias del espectador. Neurociencias y teatro, y viceversa. México: Paso de gato-Artezblai.

Stanislavski, Constantin (1979) Obras completas. El trabajo del actor sobre dí mismo en el proceso creador de la encarnación. Buenos Aires: Quetzal.

Tartarkjewicz, Władysław (1976). Historia de seis ideas. Barcelona: Tecnos.

Trancón, Santiago (2006). Teoría del Teatro. Madrid: Fundamentos.

Ubersfeld, Anne ; Pavis, Patrice (et al.) (1980). La relation téâtrale (textes réunis par Régis Durand). Lille: Presses Universitaires.

Vicentini, Claudio (2012). La teoria della recitazione. Dall'antichità al Settecento. Venezia: Marsilio.

Vischer, Friedrich (1873). Über Jas optische Formgefühl, ein Beitrag zur Ästhetik. Stuttgart: Galler. 


\section{Notas}

1 Nos referimos, en el sentido clásico, a la disciplina que estudia los factores que regulan el uso del lenguaje en la interacción social y los efectos sobre los interlocutores, lo que implica examinar no solo los aspectos semánticos sino las convenciones y estrategias derivadas de una situación comunicativa concreta, o sea, ubicada en un contexto particularizado que incluye subjetividades, intenciones, presuposiciones, etc., por las que los enunciados convergen hacia un hacer más que hacia un decir. De allí la entidad persuasiva del lenguaje. Austin (1962)

2 «si uis me flere, dolendum est/ primum ipsi tibi: tum tua me infortunia laedent» Tanto esta como todas las traducciones del latín al español pertenecen al autor del trabajo.

$3 \mathrm{Al}$ respecto, puede verse Platón, Ion, libro III, 535-536

4 Cf. Pricco, 2015, págs. 61-72. La noción de «diferencial» resulta operativa para el examen de sucesos escénicos.

5 Señalamos aquellos pasajes en los que las palabras actio/pronuntiatio pueden tener el sentido que nos incumbe: I, 10, 261; I, 15, 4; I, pr. 22; II, 12, 9; II, 15, 22; II, 34; II, 35; II, 5, 6; IV, 1, 60; IV, 1; VI; V, 10, 54; V, 6, 7; V, 7, 8; VI, 2, 35; VI, 2, 37; VIII, pr. 6; IX, 4, 138-39; X, 1, 119; X, 1, 17-19; X, 22, 3; X, 7, 9; XII, 15, 1.

6 summa enim, quantum ego quidem sentio, circa movendos adfectus in hoc posita est, ut moveamur ipsi. Nam et luctus et irae et indignationis aliquando etiam ridicula fuerit imitatio, si verba vultumque tantum, non etiam animum accommodarimus. Quid enim aliud est causae ut lugentes utique in recenti dolore disertissime quaedam exclamare videantur, et ira nonnumquam indoctis quoque eloquentiam faciat, quam quod illis inest vis mentis et veritas ipsa morum?

7 XXVII. Quare, in iis quae esse veri similia volemus, simus ipsi similes eorum qui vere patiuntur adfectibus, et a tali animo proficiscatur oratio qualem facere iudici volet. An ire dolebit qui audiet me, qui in hoc dicam, non dolentem? Irascetur, si nihil ipse qui in iram concitat ei quod exigit simile patietur? Siccis agentis oculis lacrimas dabit? Fieri non potest: XXVIII. nec incendit nisi ignis nec madescimus nisi umore «nec res ura dat alteri colorem quem non ipsa habet». Primum est igitur ut apud nos valeant ea quae valere apud iudicem volumus, adficiamurque antequam adficere conemur. 
8 Non sum nescius, quantum susceperim negotii, qui motus corporis exprimere verbis et imitari scriptura conatus sim voces. Verum nec hoc confisus sum posse fieri, ut de his rebus satis commode scribi posset, nec, si id fieri non posset, hoc, quod feci, fore inutile putabam, propterea quod hic admonere voluimus, quid oporteret: reliqua trademus exercitationi. Hoc $<$ tamen > scire oportet, pronuntiationem bonam id perficere, ut res ex animo agi videatur.

9 XXXIV. Vbi vero miseratione opus erit, nobis ea de quibus queremur accidisse credamus, atque id animo nostro persuadeamus. nec agamus rem quasi alienam, sed adsumamus parumper illum dolorem: ita dicemus quae in nostro simili casu dicturi essemus. XXXV. Vidi ego saepe histriones atque comoedos, cum ex aliquo graviore actu personam deposuissent, flentes adhuc egredi. Quod si in alienis scriptis sola pronuntiatio ita falsis accendit adfectibus, quid nos faciemus, qui illa cogitare debemus ut moveri periclitantium vice possimus?

10 XXVI...quorum induere personas quid attinet nisi adfectus adsumimus? Haec dissimulanda mihi non fuerunt, quibus ipse, quantuscumque sum aut fui, pervenisse me ad aliquod nomen ingeni credo: frequenter motus sum ut me non lacrimae solum deprenderent, sed paror et veri similis dolor.

11 animi est enim omnis actio et imago animi vultus, indices oculi: nam haec est una pars corporis, quae, quot animi motus sunt, tot significationes [et commutationes] possit efficere;[...] oculi sunt, quorum tum intentione, tum remissione, tum coniectu, tum hilaritate motus animorum significemus apte cum genere ipso orationis; est enim actio quasi sermo corporis, quo magis menti congruens esse debet [...]actio quae prae se motum animi fert, omnis movet; isdem enim omnium animi motibus concitantur et eos isdem notis et in aliis agnoscunt et in se ipsi indicant.

12 La noción de organicidad (vivencia) en la tradición stanislavskiana, se refiere a la unidad y simultaneidad entre los procesos somáticos y psíquicos del actor durante la performance como hipótesis de causa de adhesión empática del espectador a la acción escénica. La presuposición consiste en que en la medida en que no haya divorcio psicofísico la actuación resultará verosímil. Uno de los indicadores del estado de organicidad es la capacidad de resolver las vicisitudes del aquí y ahora de la escena sin salirse del rol. En el caso del orador, parece que ya Cicerón había previsto la coincidencia (un verosímil) conveniente entre un estado físico exterior ostensible y un estado «interior» inferible para afectar al interlocutor, sea éste un juez o un 
auditorio. En medio sigue estando la conmoción más que la intelección. Cf. Serrano, 2004, págs. 73-90.

13 Recordamos a partir de esta noción la escena de Hamlet de Shakespeare en la que el protagonista da consejos de interpretación a los actores y se refiere a la moderación como regla de verosimilitud. Cf. Hamlet, Act III, esc II (v.1850-1884).

14 En el libro XI de Institutio Oratoria de Quintiliano se retoma el tópico al postularse las características de la actio más conveniente. En el capítulo III, LXI-LXII, se perfilan los rasgos de la apta pronuntiatio Del mismo tenor resulta la referencia concreta a una actuación en el bic et nunc que borre las marcas del artificio que puede apreciarse más adelante en CLVI: Movendi autem ratio aut in repraesentandis est aut imitandis adfectibus (Pero el modo de mover consiste en revestirse de los afectos y representarlos en vivo).

15 En la medida en que se conciba el arte de representar como una técnica fundamentada en la adquisición de habilidades por el entrenamiento de la acción/reacción psicofísica, la categoría del «como si...» stanislavskiano opera como un estímulo para la articulación de reacciones, lógicas y emocionales. Estas respuestas conformarían la acumulación de datos y experiencia para la performance de una actuación. El personaje va construyéndose, así, como una reiteración de rasgos de conducta producidos por las reacciones a diversos estímulos. En este caso, la noción sujeto-objeto se convierte en sujeto-sujeto, entendido este último como el objeto-personaje. (Cf. Stanislavski, 1979; Magarshack, 2007, págs. 9-97).

16 Disciplina relativamente reciente que estudia el ser humano en situación de representación desde puntos de vista biológicos, psicológicos, culturales y sociales. Como discurso teórico ha tratado de explicar procesos biológicos y culturales tanto en las formas como en la estética y sentidos de las performances espectaculares. Cf. Barba y Savarese (1990) y Barba (2017).

17 Resulta pertinente remitirnos a las maneras en que fuera interpretado el teatro «épico» de Brecht y el efecto de «distanciamiento», en los que muchos críticos y teatristas entienden como una teatralidad de privilegio racional. $\mathrm{Al}$ respecto pueden verse algunas consideraciones divergentes hechas por Helene Weigel respecto de su dirección escénica de «Madre Coraje». Cf. Pricco, 2015, pág. 64.

18 Objeto teórico consistente tanto en una manipulación del espectador por parte del espectáculo (estrategias seductivo-persuasivas sobre el objeto «público») como en una participación activa del espectador (coproductor de sentido), quien, en última instancia, decide el éxito de los programas de 
acción cognitiva, afectiva y de comportamiento que la enunciación escénica intenta concretar. El concepto de «relación» cubre tanto las separaciones como las uniones, las rupturas como la continuidad, el intercambio espectacular, las presuposiciones de la enunciación escénica. En tanto categoría constituye un constructo teórico proyectado por una visión que intenta captar la unidad de una multiplicidad a partir de la consideración de la otredad. Ubersfeld, Pavis et altri (1980).

19 Nos basamos en la noción de cinfühlung (Cf. Vischer 1873; Lipps, 1924; De Marinis, 2005). 
